\title{
Tuberous sclerosis complex and sphenoid meningioma
}

\author{
Nidia Karen Castillón-Benavides', Citlaltepetl Salinas-Lara², \\ Francisco Ponce-Guerrero33, Pablo León ${ }^{4}$, \\ Noemí Gelista², Martha Lilia Tena-Suck²
}

Tuberous sclerosis complex (TSC) is an autosomal dominant multisystem neurocutaneous syndrome, genetic disease characterized by the presence of hamartomatous lesions in multiple organs (skin, brain, heart, kidneys, liver, and lungs) ${ }^{1}$. Cortical tubers, subependymal nodules and subependymal giant cell astrocytoma are the characteristic intracranial lesions of TSC ${ }^{1}$. However, the full triad occurs in only $29 \%$ of patients ${ }^{1,2}$ The majority of patients with TSC have epilepsy, although the mechanisms underlying epileptogenesis remain unknown. Tubers are traditionally thought to be stable lesions that result from abnormal corticogenesis in early fetal development.

Herein we report a 52-year-old woman without family history of neurofibromatosis type 2, with subependymal nodules, giant cell astrocytoma and infiltrating transitional meningioma.

\section{CASE}

52-year-old female, had mental disturbances history. She presented pain on the right gluteus, which made it impossible to walk; provoking several falls and left parietal-occipital oppressive cephalea and vertigo three years ago. After, she presented tonic-clonic convulsive generalized crises and progressive visual disturbances and vague speech arrests. During the physical exploration: she presented left eye exhibiting endotropy, left facial paralysis, hypoacusia, hemibody hemiparesia and cerebellar signs.

The MRI imagines presented an en- hancement dependent on the left pars petrosous that extended to the pontocerebellar angle; it was isointense on $\mathrm{T} 1$ and hyperintense on T2, reinforced homogeneously with gadolinium (Fig 1). Partial exeresis through a left petrosectomy and subtemporal approach was performed. During the surgery she presented bleeding, stroke and died 2 days after.

A complete autopsy was performed. The encephalon weight was of 1300 gr, on brain basal face observed a tumor in left temporal lobe (Figs 2A and 2B). On coronal cuts, the wall of the lateral ventricle showed bad delimited off-white zone, that was corresponded a small giant cell astrocytoma (Fig $2 \mathrm{C}$ ). The rest of the organs were normal.

Histologically the tumor was formed by meningothelial cells and numerous concentric, onion bulb structures, with lobular and fascicular arrangements (Fig 3A) and infiltrated the pituitary gland (Figs $3 \mathrm{~B}$ and 3C) and temporal bone (Fig 3D).

The normal cortical architecture was replaced by displaced neurons and glial cells (Fig 4A). The neurons displayed abnormal shapes and orientation, they contain variable amount of Nissl substance and occasionally neurofibrillary tangles (Fig 4B), and also dense fibrillary and bizarre astrocytes were observed (Fig 4C). Subependymal ventricular nodules showed atypical gliosis (Fig 4D) and large, giant, pleomorphsm and bizarrely astrocytes (Figs 4E and 4F), that was diagnosed
Martha L. Tena Suck

Av. Insurgentes Sur 3788

Col. La Fama, Tlalpan

C.P. 14269. Mexico, D.F. - Mexico

E-mail: tenasuck@yahoo.com

Received 7 July 2009

Received in final form 11 August 2009

Accepted 24 August 2009

\section{COMPLEXO ESCLEROSE TUBEROSA E MENINGIOMA DO ESFENÓIDE}

'Unidad Académica de Medicina de la Universidad Autónoma de Nayarit, México; ²Departamento de Neuropatología. Instituto Nacional de Neurología y Neurocirugía Manuel Velasco Suárez, México; ${ }^{3}$ Servicio de Neurocirugía, Instituto Nacional de Neurología y Neurocirugía Manuel Velasco Suárez, México; ${ }^{4}$ Servicio de Neuropsiquiatría, Instituto Nacional de Neurología y Neurocirugía Manuel Velasco Suárez, México. 


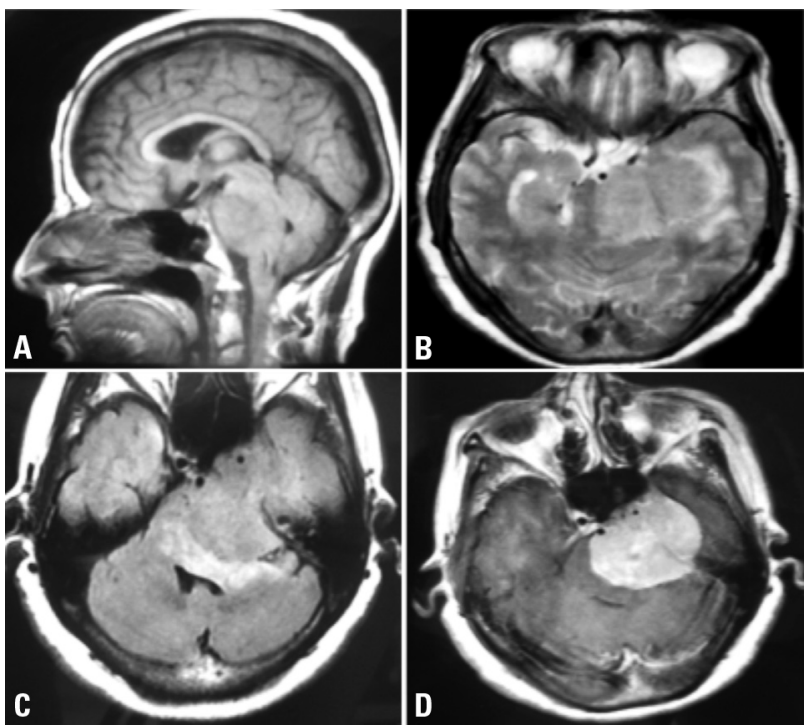

Fig 1. [A] MRI-scan, sagittal images in T1. They showed an image with tumoral aspect and irregular edges at the left sinus cavernous. [B] Axial images in T2, mild edema at the peritumoral white matter was observed. [C] Axial MRI- scan in FLAIR sequence showed peritumoral edema, along with the tumoral mass effect that moves and compresses the fourth ventricle. [D] Axial MRI-scan in TI post gadolinium

as subependymal giant cell astrocytoma. It was GFAP and NSE immunoreactions positive and also white matter heterotopias were observed. The rest of the autopsy was normal.

\section{DISCUSSION}

Tuberous sclerosis is a multisystem disorder characterised by the formation of hamartomas in various parts of the body. We present a patient who presented three characteristic lesions of this rare disease: such as, cortical tubers, subependymal nodules, subependymal giant cell astrocytomas ${ }^{1-3}$, and meningioma, that not this considered like part of this disease, which was peculiar to this case. The association of the three lesions suggests a possible common connective-tissue defect.

Neurofibromatosis type 1 and 2 and tuberous sclerosis very seldom occur together but is common in meningioma association. There is immense variability in the clinical presentation of tuberous sclerosis and many incomplete forms (formes frustes) exist ${ }^{1-3}$. The presence of meningiomas and skin melanomas in glioma families may indicate a novel association as a cancer susceptibility trait ${ }^{4}$. Irving RM et al. ${ }^{5}$, reported the first case of a tuberous sclerosis patient with a maxillary antral meningioma.

Malformations of cortical development are classified on the basis of imaging features and stages of cortical development ${ }^{5}$. Those are grouped by abnormal glial and neuronal proliferation, migration and cortical organization. Non-neoplastic forms include focal cortical dysplasia and tuberous sclerosis, resemblance to astrocytes and ganglion cells, its histogenesis remains controversial ${ }^{6,7}$.

Gliomas of the CNS associated with tuberous sclerosis have been well documented ${ }^{6-8}$. This occurrence suggests that neoplasms arising from hematoma and may behave differently from those CNS tumors that arise apparently de novo ${ }^{6}$.

Subependymal giant cell astrocytomas are slowly growing tumors corresponding to WHO grade $\mathrm{I}^{6-7}$, accounted for $0.16 \%$ of intracranial tumors and $0.51 \%$ of all gliomas reported and shows varied histology consisting of sweeping bundles of spindle cells, gemistocyte and ganglion-like cells with interspersed inflammatory cell component ${ }^{6}$. Immunoreactivity for GFAP, NF, S-100, NSE and synaptophysin indicates that this is a hybrid tumor with glial and neuronal differentiation ${ }^{6,7}$. Although giant cell astrocytoma may develop from these subependymal nodules, tumor formation is very rare in the cortical nodules ${ }^{7}$.

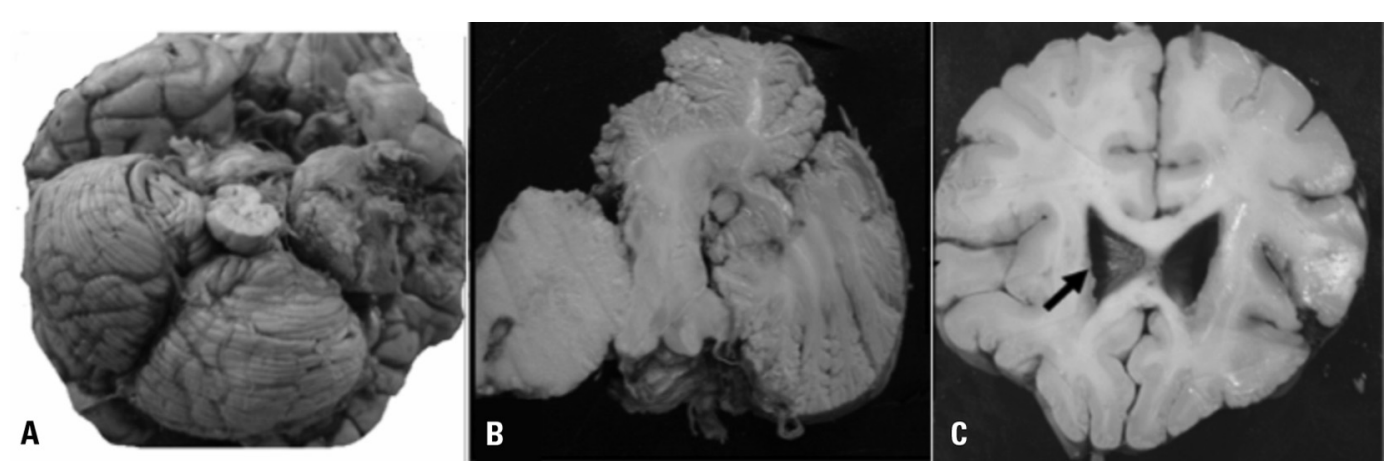

Fig 2. Gross aspect of encephalon [A] Basal surface observed a tumor in left temporal lobe; it was soft, haemorrhagic and necrotic. [B] On coronal cut off-white tumor was observed, it was apparently encapsulated, that it corresponded a meningioma, which compressed normal cerebral structures and [C] On coronal cut observed on the wall of the lateral ventricle a bad delimited off-white zone, that was corresponded a small giant cell astrocytoma. The arrow showed the astrocitoma. 

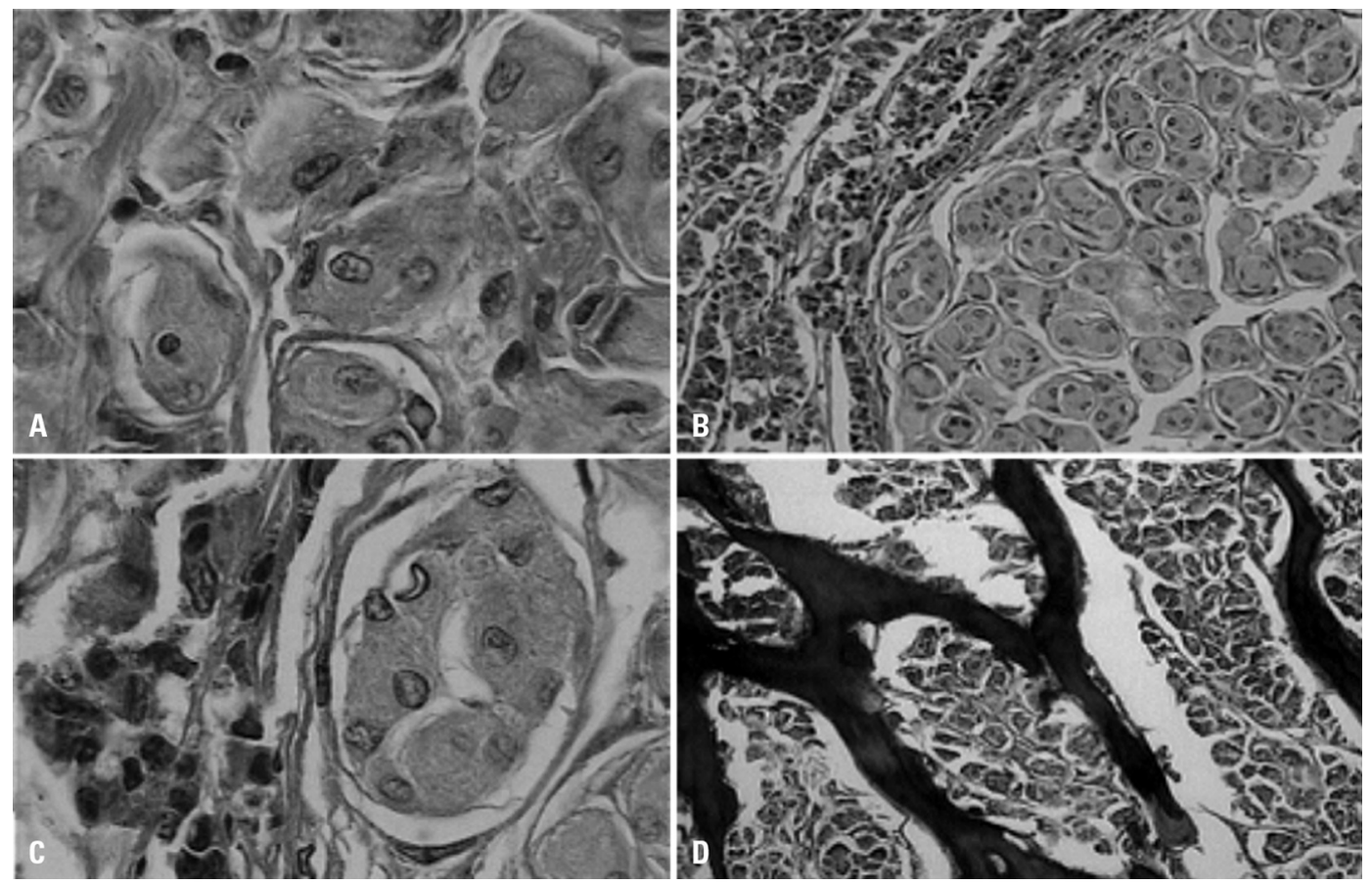

Fig 3. Histological features of meningioma: [A] Tumor was formed by numerous, concentric, onion bulb structures (H\&Ex400). Tumor infiltrated pituitary gland (H\&Ex400). [B] Close up of adenohypophysis showed vascular permeation of meningothelial cells (H\&EX400). [C] Neurohypophysis showed meningioma infiltration (H\&E x400). [D] Osseous diffuse infiltrate of meningioma (H\&E x200).
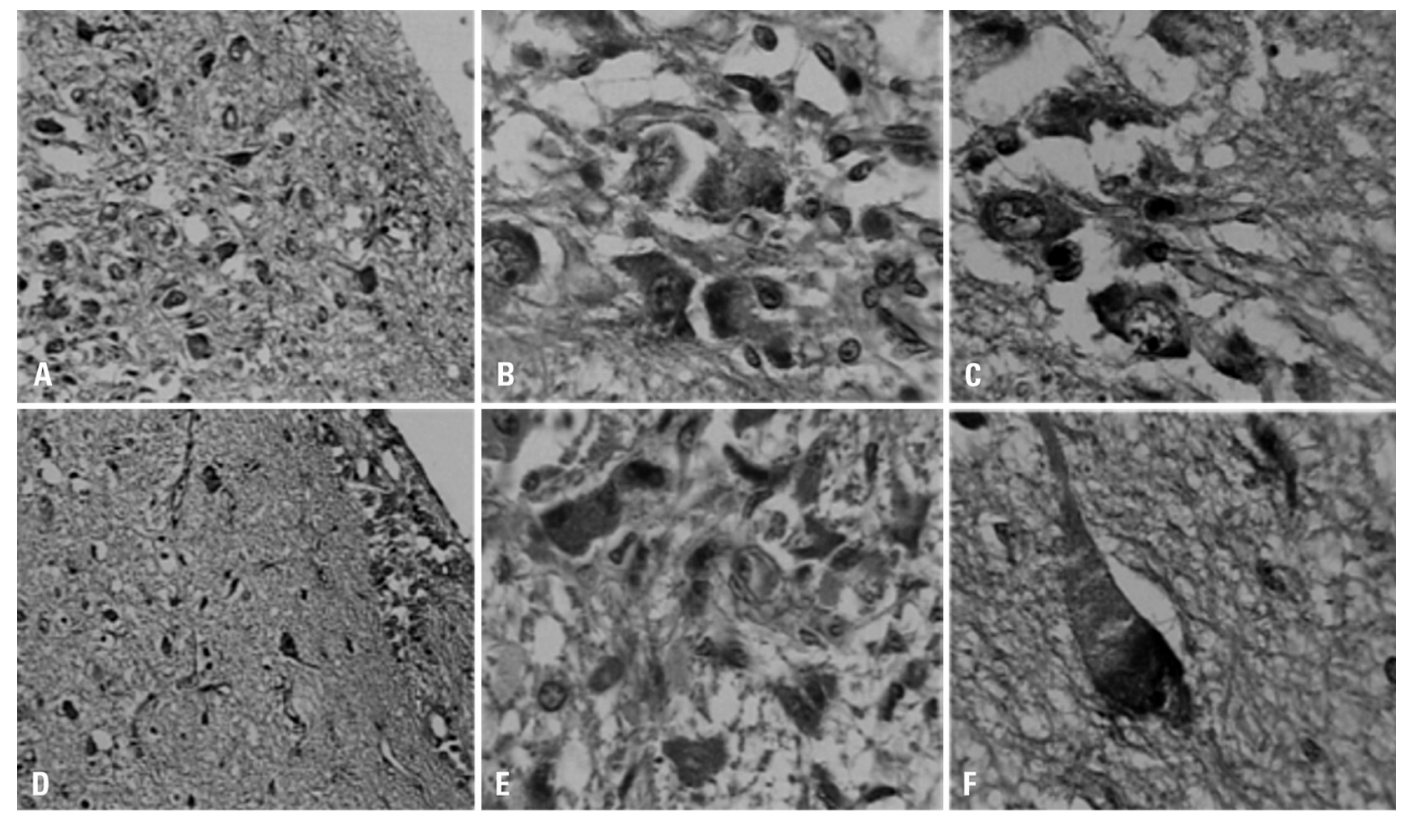

Fig 4. Histological findings [A] The normal cortical architecture is replaced by dysplasic neurons and glial cells (H\&Ex20). [B and C] Cortical neurons display abnormal shapes and orientation, the astrocytes are bizarre (H\&Ex40). [D] subependymal ventricular nodules showed fibrillar and atypical astrocytes (H\&Ex200). [E] These astrocytes are large often bizarrely gigantic and many form clusters (H\&Ex400), and [F] Close up of bizarre and giant cell astrocytes (H\&Ex400). 
However, fibrillary astrocytoma may be originating from a cortical tuber ${ }^{3}$.

We favored the hypothesis of the simultaneous occurrence of the two tumors rather than a common pathway giving rise to two tumor entities, or may be we have to differentiate it from a cerebral collision tumor in which a convexity meningioma was invaded by astrocytoma ${ }^{4,5}$. We present a second case report about this rare association without neurofibromatosis stigmata.

\section{REFERENCES}

1. Roach ES, Gomez MR, Northrup H. Tuberous sclerosis complex consensus conference: revised clinical diagnostic criteria. J Child Neurol 1998;13:624

2. Jozwiak S, Schwartz RA, Janniger CK, Bielicka-Cymerman J. Usefulness of di- agnostic criteria of tuberous sclerosis complex in pediatric patients. J Child Neurol 2000;15:652-659.

3. Eren $S$, Polat P, Erman Z. An unusual tuberous sclerosis case presenting with fibrillary astrocytoma. Pediatr Neurosurg 2002;37:118-121.

4. Drlicek M, Aichholzer M, Wurm G, Bodenteich A, Fischer J. Collision tumour composed of glioblastoma and meningioma: a Case report. Pathologe 2004; 25:402-405.

5. Irving RM, Ford GR, Jones NS. Tuberous sclerosis with primary meningioma of the maxillary antrum. J Laryngol Otol 1991;105:481-483.

6. Sharma MC, Ralte AM, Gaekwad S, Santosh V, Shankar SK, Sarkar C. Subependymal giant cell astrocytoma, a clinicopathological study of 23 cases with special emphasis on histogenesis. Pathol Oncol Res 2004;10:219-224.

7. Ess KC, Kamp CA, Tu BP, Gutmann DH. Developmental origin of subependymal giant cell astrocytoma in tuberous sclerosis complex. Neurology 2005; 64:1446-1449.

8. Jozwiak J, Jozwiak S. Giant cells: contradiction to two-hit model of tuber formation. Cell Mol Neurobiol 2005;25:795-805. 